\title{
Research on the Structural Optimization Design of ER300 Palletizing Robot
}

\author{
Ning Kunpeng, Li Dongbo, He Fei*, Tong Yifei and Zhang Kai \\ School of Mechanical Engineering 402, Nanjing University of Science and Technology, Nanjing, Jiangsu, 210094, \\ China
}

\begin{abstract}
DOF (Four degrees of freedom) palletizing robot is widely used in our country, which is playing a more and more important role in the logistics automation. The important indicators of ER300 palletizing robot performances include strength, stiffness, and ER300 palletizing robot weight, which mainly depend on the structural design of ER300 palletizing robot. So it is of importance to research on the structural optimization design by means of finite element analysis (FEA), ADMAS and Matlab. In this paper, the framework of structural optimization design is proposed. Secondly, taking ER300 palletizing robot as research object, its structure is described and the finite element (FE) model of the palletizing robot is developed for the finite element analysis. Thirdly, to ensure the reliability of the results of the analysis, stress and strain experiment is carried out to validate the analysis results. Finally, the structural optimization design of major parts has been completed. The results show that structural optimization design can reduce total mass of ER300 palletizing robot greatly by using the finite element analysis and optimization technology premised on the design requirements of palletizing robot such as stiffness, strength and so on, thus the structural optimization design can be achieved.
\end{abstract}

Keywords: 4-DOF palletizing robot, ABAQUS, Stress and strain experiment, Structural optimization design.

\section{INTRODUCTION}

Palletizing robot is playing an increasingly important role in the field of logistics automation. It can complete the stacking accurately and efficiently, which can reduce the labor intensity of workers and improve the production efficiency $[1,2]$. Palletizing robot's research in the United States and other developed countries has achieved great successes. But domestic palletizing robot in terms of research and development is still in the initial stage [3-5]. With the rapid development of national economy and the enlargement of the scale of production, the mechanical automation level of the enterprise is rising. The contemporary automation techniques have been widely used for different fields such as: the research about global threshold of image, the research about river forecasting, water level prediction, and the discharges forecasting of the daily and monthly river flow, and the research about construction claims. The palletizing robot which is a kind of important application of the automation techniques has also been widely used, due to its wide application range, good flexibility, low cost etc [6-10].

At present, as the product is still in the initial stage, empirical design is often used for the structural design of palletizing robot. The rationality and scientific of the structure with the traditional design method have no reliable theory basis and it also can bring a lot of disadvantages [11-13]. On one hand, there may be local structure is too strong. The

*Address correspondence to this author at the School of Mechanical Engineering 402, Nanjing University of Science and Technology, Nanjing, Jiangsu, 210094, China; E-mail: db_tyf@aliyun.com weight of the arm and the inertia force are too big etc. All of these factors will bring the adverse effects to the normal operation of the palletizing robot [14]. On the other hand, the strength of the local structure may be insufficient, which may affect the overall stiffness of the robots and led to early damage in the process of use [15]. With the rapid development of finite element analysis (FEA) technique, the traditional design method is gradual replaced by finite element analysis and design. There is quite a lot of CAE (Computer Aided Engineering) software, such as: ANSYS, ABAQUS, etc $[16,17]$. The stress distribution of parts before and after optimization under the risk position can be gained by ABAQUS analysis. To ensure the reliability of the results of the analysis, stress and strain experiment is carried out to validate the analysis results. In the process of research, we confront the following three aspects' difficulties and challenges. How to build the finite element model? How to get experimental stress? How to optimize the structure of the parts? Through the discussing between team members, the solutions are finally obtained. In order to build the finite element model, first, build the geometric modeling by solidworks, then imported to ABAQUS, finally, simplified its connection relationship and the force. The experimental stress was got through the static strain gauge, which is the special software for measuring stress and strain and its sensitivity is high. In order to get the optimal structure, the structural optimization mathematical model is proposed, which takes the minimum volume as objective function. The structure is optimized through changing each feature sizes or digging holes. 
The present work was carried out to obtain simulation data of the palletizing robot. In the next section, the framework of ER300 palletizing robot optimization design is proposed. In Section 3, FE model of ER300 palletizing robot is developed using commercial program ABAQUS and the loading and the results of finite element analysis are given and discussed. In Section 4, stress and strain experiment is carried out to validate the analysis results, thus ensuring the reliability of the results of the analysis. The results of experiment are also given and discussed. In Section 5, shape, size and topology optimization are further carried out as well as comprehensive optimization and the results of structural optimization are analyzed. Finally, research conclusions are summarized.

Through the strength analysis and optimization design for the structure of the robot by CAD/CAE technology, we can get a basic understanding of the product before being produced $[18,19]$. As we can know the overall quality, reliability and security of the palletizing robot before being produced, it reduced the product cycle from design to enter the market which reduces the design cost and brings huge economic benefits for the enterprise. Through the structural optimal design to weight loss, we can save materials and reduce energy consumption. It also can reduce the inertia force and dynamic load produced during the machine operation, which is conducive to the normal operation of the machine. So the strength analysis and optimization design for the structure of the palletizing robot is of great importance [20].

\section{STRUCTURAL OPTIMIZATION DESIGN FRAME WORK OF ER300 PALLETIZING ROBOT}

The presented research on ER300 palletizing robot is the structural optimization design technology. It mainly includes the following three aspects:

1) The finite element analysis (FEA) before optimization

It is mainly in order to get the stress distribution of the parts under the risk position before optimization. We can further get the maximal stress and maximal displacement. According to the result, we can know that whether the structural strength of the parts have optimizing space.

2) Stress and strain experiment to validate the finite element analysis results

The stress get by experiment is the actual working condition's stress of the palletizing robot. The stress get by the finite element analysis (FEA) is the theoretical value of the palletizing robot. Through comparing the results of the two, we can verify the correctness of the finite element model and boundary conditions.

\section{3) Structural optimization}

It is mainly in order to get the stress distribution of the parts under the risk position after optimization and the maximum stress and maximum displacement. Under this case that the maximal stress and the maximal displacement didn't exceed the allowed range, reduce the weight of the palletizing robot as much as possible. Thus the purpose of structural lightweight can be achieved.
Through the study of the structural characteristics of the palletizing robot's geometric model and the actual working condition, and with the aid of finite element analysis software, the optimization design of palletizing robot's main parts is completed. According to the above research contents, the optimization design framework can be illustrated as shown in Fig. (1).

\section{THE FINITE ELEMENT ANALYSIS (FEA) BE- FORE OPTIMIZATION}

ER300 palletizing robot has many parts, but each part optimization design method is almost the same, so we just select the forearm and wrist of ER300 palletizing robot as an example to illustrate.

\subsection{Be Imported into the ABAQUS}

According to the engineering drawing, geometric model of the palletizing robot is established by SOLIDWORKS. Open the ABAQUS software and import the geometric model into the ABAQUS through the "import" button. The simplified geometric model of forearm is shown in Fig. (2) and the simplified geometric model of wrist is shown in Fig. (3). The basic dimensions of forearm as follows: length is 1425 $\mathrm{mm}$, wall thickness is $10 \mathrm{~mm}$, and maximal width is 160 $\mathrm{mm}$. The basic dimensions of wrist as follows: the maximal height is $380 \mathrm{~mm}$, length is $339 \mathrm{~mm}$, the distance between two holes of the front is $210 \mathrm{~mm}$, and the distance between two holes of the side is $400 \mathrm{~mm}$.

\subsection{Mesh Partitioning}

Before the mesh, the small edge and the small surface should be merged. The imported model contains some connectivity error or some other defects, so the above operation should be carried out after importing file model. The unnecessary details should be removed, such as chamfer, convex platform, threaded holes, etc. These details characteristics will affect its grid size, change the distribution of network structure, increase the network density, which not only affect the results of the analysis, it can also cause exponentially increase the amount of calculation. It eventually affects the results of the analysis. Finer the elements meshed are, more accordant the partitioned model is with the actual condition.

As the shape of the parts is irregular, the best parameters of the grid can't be got at once. It needs multiple partitions to obtain the best parameters which include the size of the grid and the type of grid and grid the layout of the grid's seed. So Grid division generally is not can be done at once and need for many times. So first to set up a global seed size, cell type, mesh type, simple classification. Then through the 'Verify Mesh' button for grid quality inspection, find out the corresponding warning information and error information, analyze the reason of these information, modified the geometry model and then the new mesh. For example, as a result of the action of tensile excision, the inner wall of the forearm and wrist produced small sharp corners. Because the sizes of two adjacent holes' diameter are almost the same in the ladder holes, it produced a small circular surface. In these places 


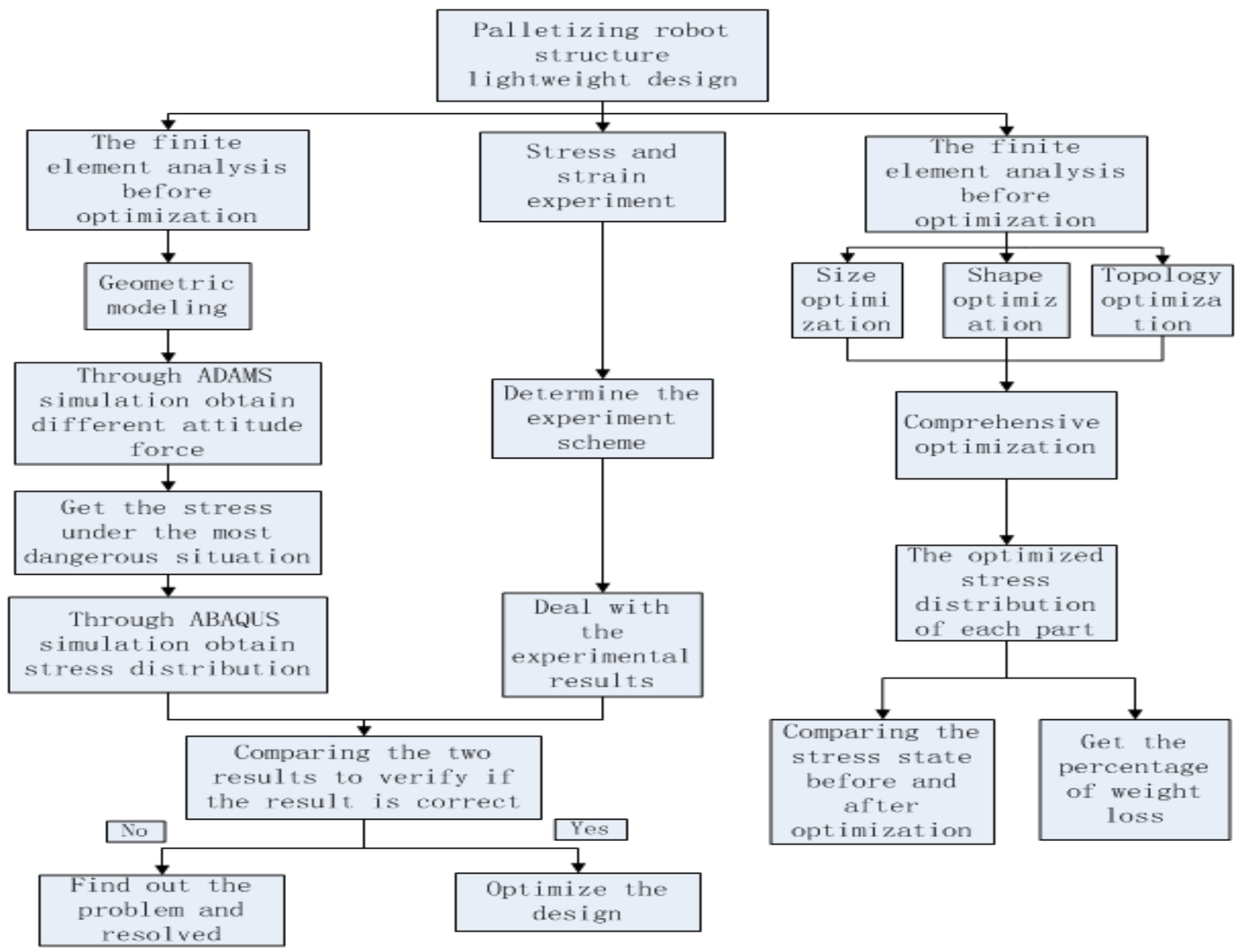

Fig. (1). The optimization design framework.

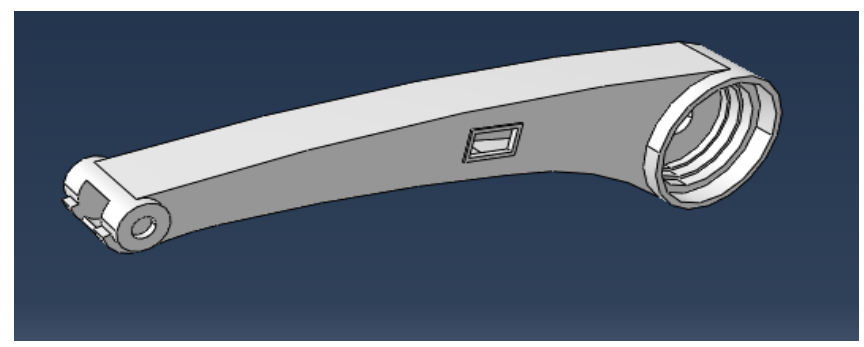

Fig. (2). The ABAQUS model of the forearm.

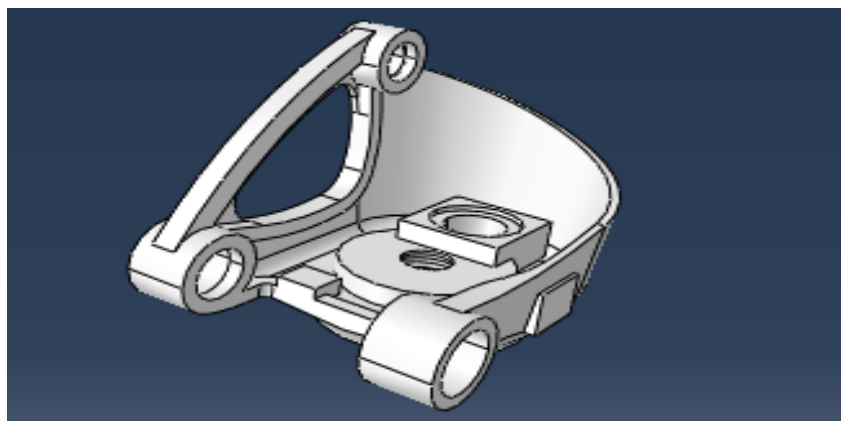

Fig. (3). The ABAQUS model of the wrist. 


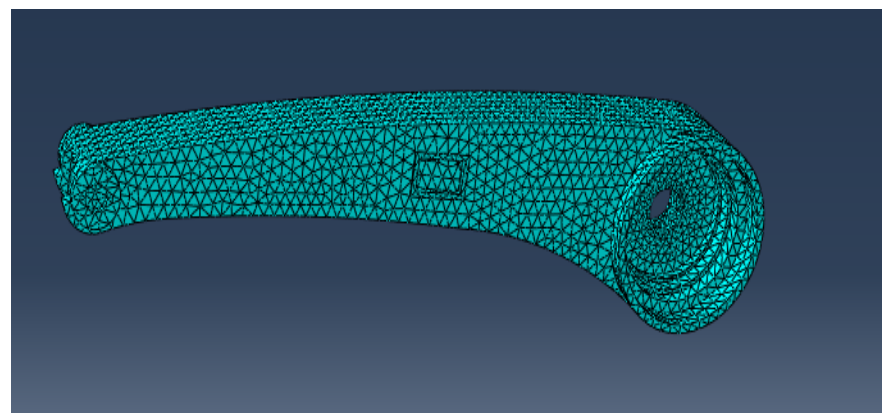

Fig. (4). Ultimately meshed grid model of forearm.

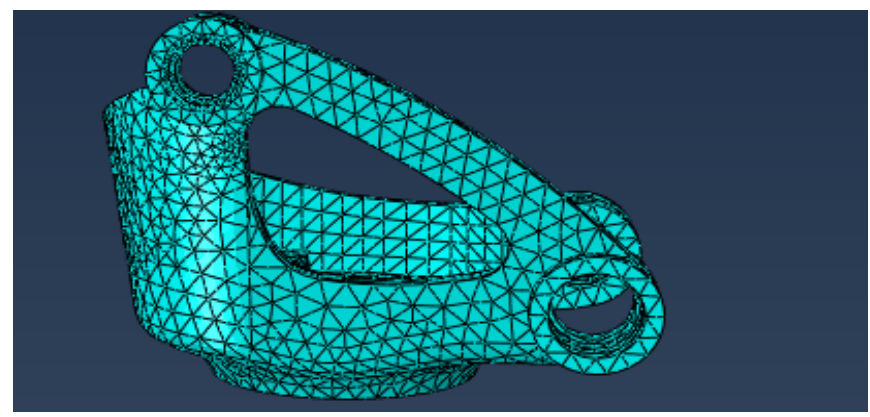

Fig. (5). Ultimately meshed grid model of wrist.

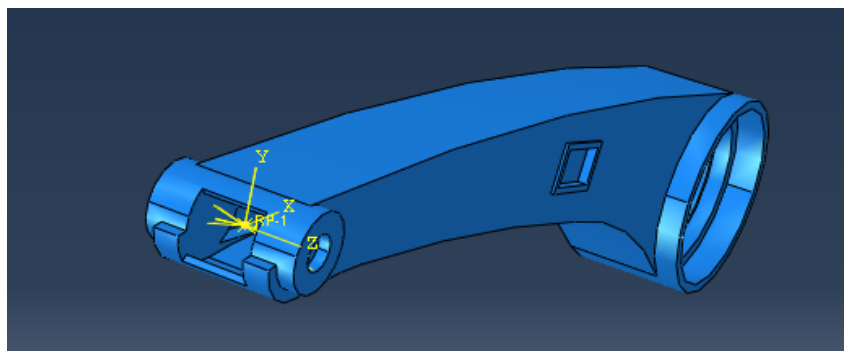

Fig. (6). Coupling constraints of forearm.

there are many warning. We can modify the geometry model to eliminate the small sharp corners and we also can refine the seeds on the circular surface to eliminate the warning. Ultimately meshed grid model of forearm is shown in Fig. (4) and ultimately meshed grid model of wrist is shown in Fig. (5).

\subsection{The Definition of Load and Boundary Conditions}

Fixed constraint of forearm is imposed in the place where forearm is connected to the big arm. It limits the forearm's six degrees of freedom. Forearm in total suffers two forces and a torque, respectively their own gravity, the force and the moment of wrist body to forearm. Their own gravity is $1470 \mathrm{~N}$. The force of wrist body to forearm for the $\mathrm{X}$ direction is $10466.5 \mathrm{~N}$ and for the $\mathrm{Y}$ direction is $-5720.1 \mathrm{~N}$. The moment of wrist body to forearm for the $\mathrm{X}$ direction is 994100 N.mm and for the $\mathrm{Y}$ direction is 3171300 N.mm. The constraint of wrist body to forearm simplified to coupling constraint. Then we can apply distribution coupling constraint on the joint where wrist is connected to the forearm and impose the force and moment on the reference point to simulate the effect of wrist body to forearm. The coupling constraint is shown in Fig. (6). The loads and boundary conditions which are applied are shown in Fig. (7).

Fixed constraint of wrist is imposed in this place where wrist is connected to the forearm. It limits the wrist's six degrees of freedom. Wrist in total suffers three forces, respectively their own gravity, and the force of load to wrist, the force of forearm vice stem to wrist. Their own gravity is $441 \mathrm{~N}$. The force of the load to wrist $2940 \mathrm{~N}$ and direction is vertical. The force of forearm vice stem to wrist for the $\mathrm{X}$ direction is $10502.5 \mathrm{~N}$ and for the $\mathrm{Y}$ direction is $-2004.68 \mathrm{~N}$. The constraint of load to wrist and the constraint of forearm vice stem to wrist both simplified to coupling constraint. Then we can apply distribution coupling constraint on the place where load is connected to the wrist and the joint forearm vice stem is connected to wrist. After all this completed, we can impose the force and moment on the reference point 


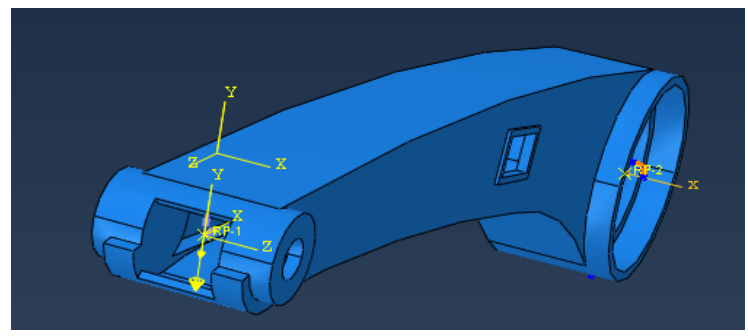

Fig. (7). Load and boundary conditions of forearm.

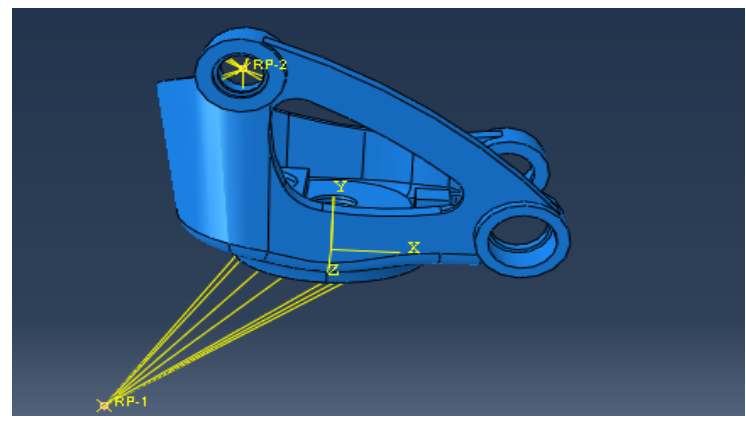

Fig. (8). Coupling constraints of wrist.

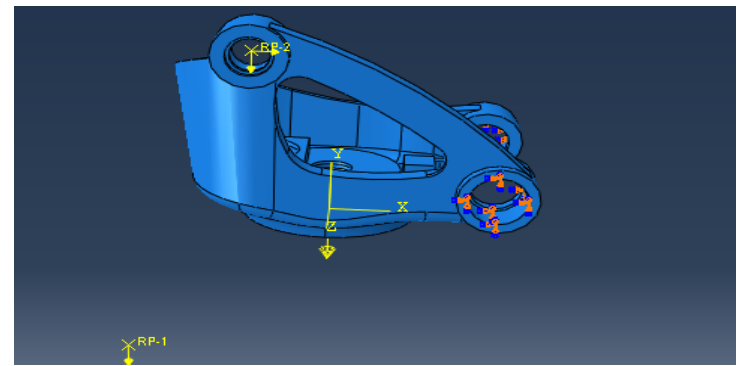

Fig. (9). Load and boundary conditions of wrist.

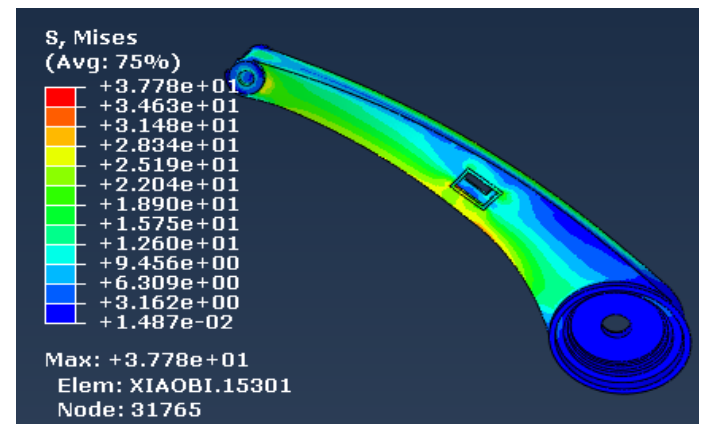

Fig. (10). The stress cloud of forearm.

to simulate the effect of load to wrist and the effect of forearm vice stem to wrist. The coupling constraint is shown in Fig. (8). The loads and boundary conditions which are applied are shown in Fig. (9).

\subsection{Post-processing Results}

After the definition of load and boundary conditions and grid division are both completed, we can use ABAQUS to simulation and obtain the stress cloud and the displacement cloud. The stress cloud and the displacement cloud of forearm are respectively shown in Fig. (10) and Fig. (11). The stress cloud and the displacement cloud of wrist are respectively shown in Fig. (12) and Fig. (13).

From the picture of stress cloud and the displacement cloud above, we can know that the maximum stress suffered by forearm is $37.78 \mathrm{MPa}$ and the maximal stress suffered by wrist is $36.64 \mathrm{MPa}$.The material of the two parts is QT40018 , its yield strength is $250 \mathrm{MPa}$ and its tensile strength is 


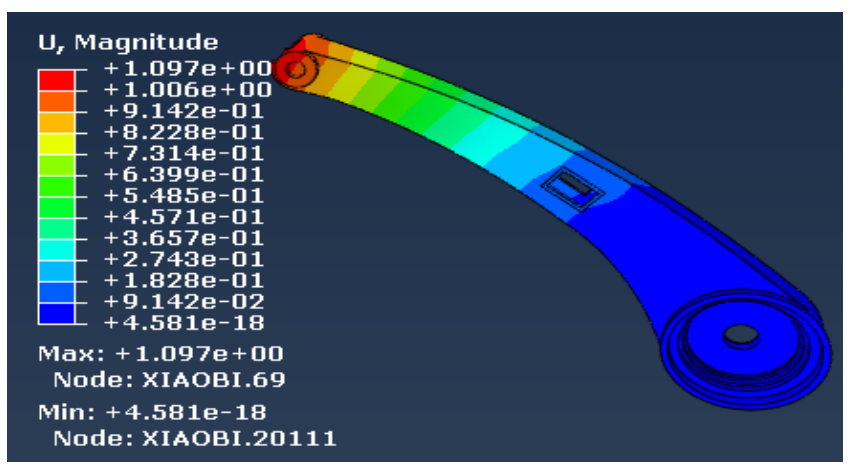

Fig. (11). The displacement cloud of forearm.

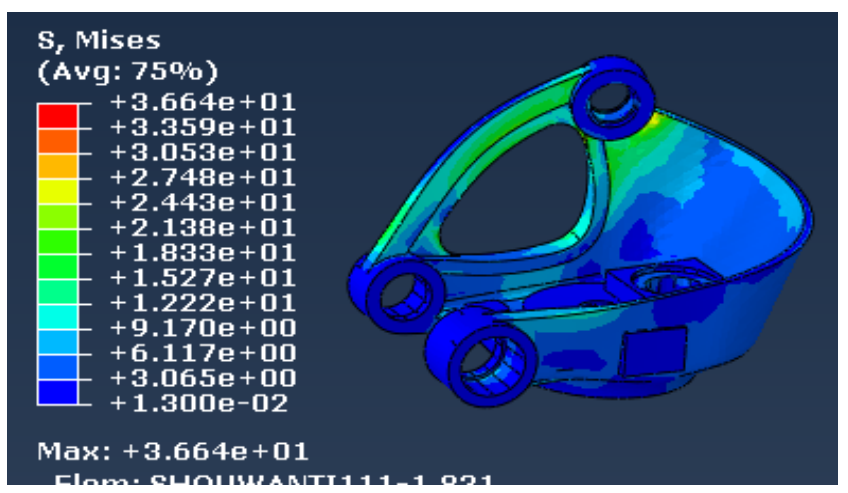

Fig. (12). The stress cloud of wrist.

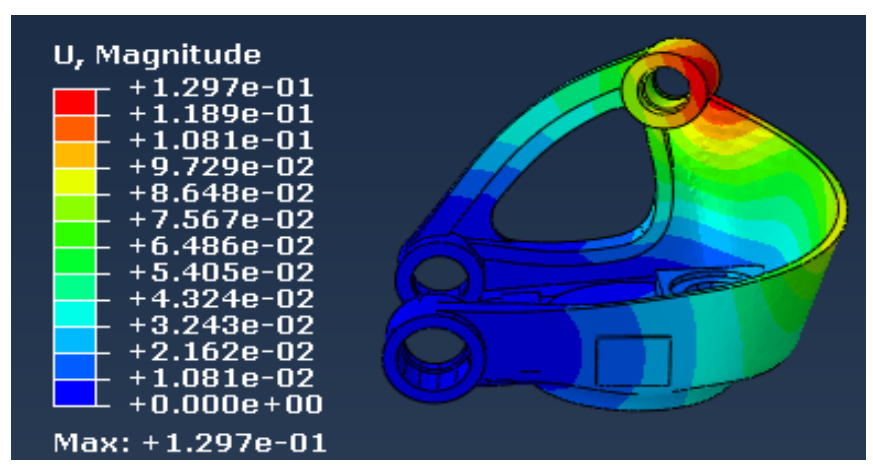

Fig. (13). The displacement cloud of wrist.

$400 \mathrm{MPa}$. As its strength is far meet the design requirements, the structure of the two parts existence very big margin in terms of strength and structure optimization design. The maximal displacement of forearm is $1.097 \mathrm{~mm}$ and the maximum displacement of wrist is $0.1297 \mathrm{~mm}$. Compared with the size of the parts, their displacement is small and the deformation almost can be ignored. They can well meet their location accuracy requirement.

\section{STRESS AND STRAIN EXPERIMENT TO VALI- DATE THE FINITE ELEMENT ANALYSIS RESULTS}

\subsection{The Introduce of the Experiment}

This experiment use strain foil to test stress of the main parts. As the palletizing robot suffers complex force, not only bearing the forces but also bearing the torque, we choose the strain rosette to test the stress. This strain rosette has three pins of different direction, whose direction is respectively 0 degrees, 45 degrees, 90 degrees. The strain rosette through wires is connected with the static strain gauge and then the static strain gauge is connected with the computer. Through the calculation of static strain gauge, the maximum stress of the tested point can be got. The results will be shown on the computer. The static strain gauge is the special software for measuring stress and strain, whose measuring range is from $-2000 \mu \varepsilon$ to $+2000 \mu \varepsilon$ and the sampling frequency is $2 \mathrm{~Hz}$ and the sensitivity is $0.1 \mu \varepsilon$. In order to reduce the random error, each measured point is tested for five times. The final result is the average number of the five measurements.

According to the results of stress distribution get by the finite element analysis, we choose 2 point to paste strain rosette. These strain rosette are pasted the place where it 


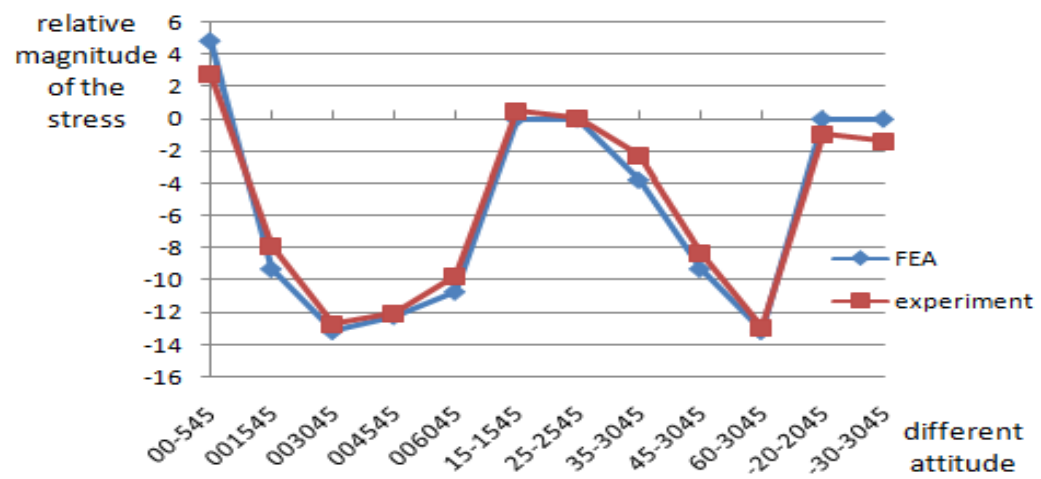

Fig. (14). The contrastive curve of forearm.

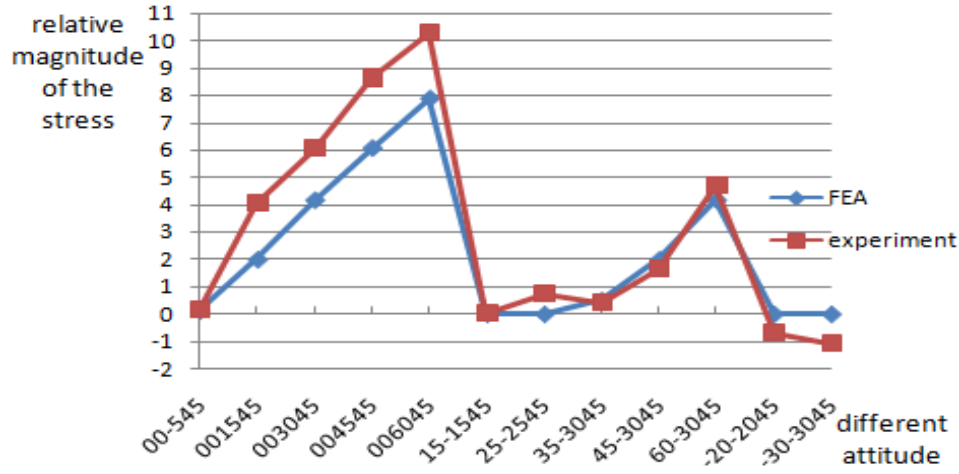

Fig. (15). The contrastive curve of wrist.

suffers much bigger force or its structure is special. This test was conducted under the condition of the practical work of palletizing robot. The measured results can better reflect the real stress of the palletizing robot under the actual working condition. Experimental results with finite element analysis results verify each other, thus ensuring the reliability of the finite element analysis results. The contrastive curves of experimental results and finite element's result are shown in the Fig. (14) and Fig. (15). Abscissa represents different gestures and ordinate represents relative magnitude of the stress.

\subsection{The Analysis of the Experimental Results}

From the picture of contrastive curves above, we can easily know that despite the stress value of the two curves has a subtle difference, but the overall trend is consistent. So we can obtain the conclusion that the result of finite element analysis is correct and reliable. This subtle difference is caused by the following reasons:

1) As the force suffered by the parts and the connection between parts are complex, the finite element model are correspondingly simplified. So it has little different with real situation.

2) The strain rosette has its own size and the measurement tested by strain rosette is the stress of the little areas, but the measurement tested by the finite element is the stress of a point. So the two curves have a subtle difference.
3) There are all kind of interferential factors such as noise and vibrations in the actual measurement environment, which also affects the result of the experiment.

These factors above are inevitable. As the existence of these factors, a subtle difference between the two contrastive curves was arisen. But the deviation is very small and the little deviation is acceptable.

\section{STRUCTURAL OPTIMIZATION}

The structural optimization mathematical model of forearm is proposed as follows which takes the minimum volume as objective function, each feature sizes as design variables, and the scopes of stress, strain energy, modal as constraints:

$$
\begin{aligned}
& \text { Min V }(\mathrm{X})=\mathrm{V}(\mathrm{x} 1, \mathrm{x} 2, \mathrm{x} 3) \\
& \mathrm{C}_{\mathrm{j}}=\frac{1}{2} \mu_{j}^{T} f_{j} \leq 1.1 \times 10^{7} \mathrm{j}=1,2,3,4,5 \mathrm{C}_{\mathrm{j}}=\frac{1}{2} \mathrm{u}_{\mathrm{j}}^{\mathrm{T}} \mathrm{f}_{\mathrm{j}} \leq \\
& \begin{aligned}
1.1 \times 10^{7} \mathrm{Jj} & =1, \ldots, 5 \\
\mathrm{~S} . \mathrm{T} \quad \mathrm{Ku}=\mathrm{f} & \leq 167 \mathrm{MPa} \\
& F \geq 3
\end{aligned}
\end{aligned}
$$

Where, $\mathrm{V}(\mathrm{X})$ denotes the total volume of forearm; X1 denotes wall thickness; X2 denotes the hole size of the forearm's side; X3 denotes the hole size of the forearm's 


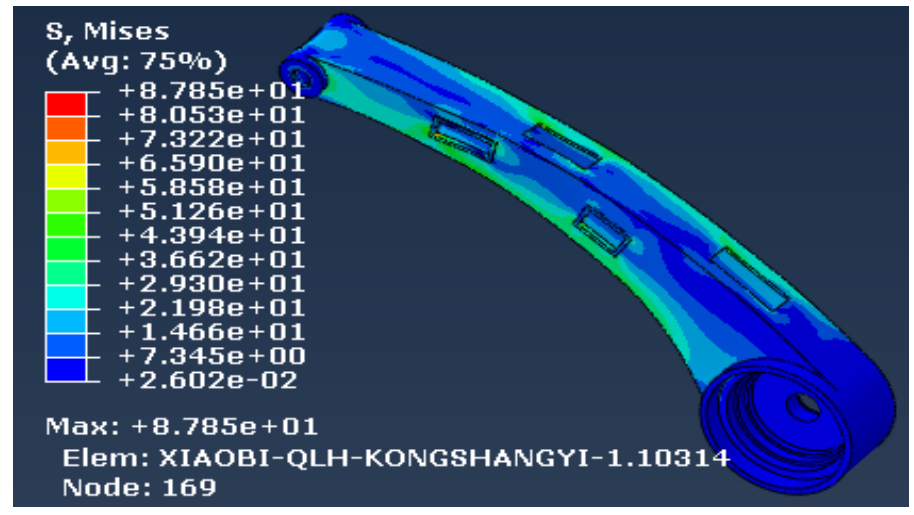

Fig. (16). The stress cloud of forearm.

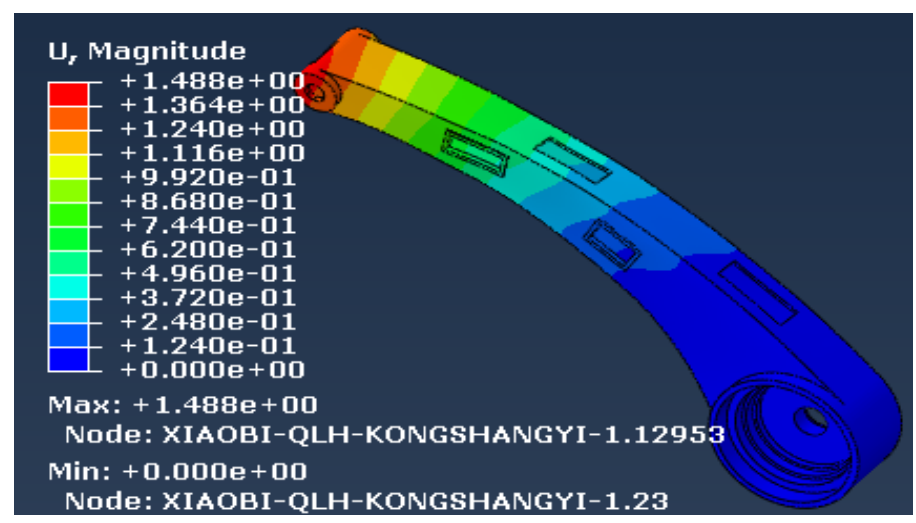

Fig. (17). The displacement cloud of forearm.

upper surface; $C_{j}$ denotes the total strain energy of forearm under the $\mathrm{j}^{\text {th }}$ load; $\mathrm{K}$ denotes the stiffness matrix of the system; f denotes the load; $\mathrm{u}$ denotes the node displacement vector under the load f; $\sigma$ odenotes the stress; $\mathrm{F}$ denotes the natural frequency. Objective function $\mathrm{V}(\mathrm{X})$, constraint function $\mathrm{C}_{\mathrm{j}}$ and $\sigma \sigma$ can be obtained from structural response of the finite element analysis. The size of X1 changed from $10 \mathrm{~mm}$ to $8 \mathrm{~mm}$, the size of $\mathrm{X} 2$ is $140 \mathrm{~mm} \times 50 \mathrm{~mm}$, and the size of $\mathrm{X} 3$ is $160 \mathrm{~mm} \times 80 \mathrm{~mm}$. The stress cloud and the displacement cloud of forearm after structural optimization are respectively shown in Fig. (16) and Fig. (17).

The structural optimization mathematical model of wrist is proposed as follows which takes the minimum volume as objective function, each feature sizes as design variables, and the scopes of stress, strain energy, modal as constraints:

$$
\begin{aligned}
& \quad \operatorname{Min} \mathrm{V}(\mathrm{X})=\mathrm{V}(\mathrm{x} 1, \mathrm{x} 2, \mathrm{x} 3, \mathrm{x} 4) \\
& \mathrm{C}_{\mathrm{j}}=\frac{1}{2} \mu_{j}^{T} f_{j} \leq 1.1 \times 10^{7} \mathrm{j}=1,2,3,4,5 \mathrm{C}_{\mathrm{j}}=\frac{1}{2} \mathrm{u}_{\mathrm{j}}^{\mathrm{T}} \mathrm{f}_{\mathrm{j}} \leq 1.1 \times \\
& 10^{7} \mathrm{Jj}=1, \ldots, 5 \\
& \quad \mathrm{~S} . \mathrm{T} \mathrm{Ku}=\mathrm{f} \\
& \sigma \leq 167 M P a \\
& F \geq 3
\end{aligned}
$$

Where, $\mathrm{V}(\mathrm{X})$ denotes the total volume of wrist; X1 denotes wall thickness; X2 denotes wrist's rod thickness; X3 denotes the hole size; $\mathrm{X} 4$ denotes the remove size of the front surface; $C_{j}$ denotes the total strain energy of wrist under the $\mathrm{j}^{\text {th }}$ load; $\mathrm{K}$ denotes the stiffness matrix of the system; $\mathrm{f}$ denotes the load; $\mathrm{u}$ denotes the node displacement vector under the load $\mathrm{f}$; $\sigma$ denotes the stress; $\mathrm{F}$ denotes the natural frequency. Objective function $\mathrm{V}(\mathrm{X})$, constraint function $\mathrm{C}_{\mathrm{j}}$ andocan be obtained from structural response of the finite element analysis. The size of X1 changed from $10 \mathrm{~mm}$ to $8 \mathrm{~mm}$, the size of X2 changed from $20 \mathrm{~mm}$ to $18 \mathrm{~mm}, \mathrm{X} 3 \mathrm{de}-$ notes the hole size and its diameter is $189 \mathrm{~mm}$, and the size of $\mathrm{X} 4$ is $45 \mathrm{~mm} \times 140 \mathrm{~mm} \times 245 \mathrm{~mm}$. The stress cloud and the displacement cloud of wrist after structural optimization are respectively shown in Fig. (18) and Fig. (19).

The final optimization results are shown in the Table $\mathbf{1 .}$

From the Table 1 above, we can know that the maximal stress suffered by forearm after optimization is $87.85 \mathrm{MPa}$ and the maximal stress suffered by wrist after optimization is $43.07 \mathrm{MPa}$. The material of the two parts is QT400-18, its yield strength is $250 \mathrm{MPa}$ and its tensile strength is $400 \mathrm{MPa}$. The parts after structural optimization satisfy the requirement of strength. Compared with the displacements before structural optimization, the displacements after structural optimization changed very little. They completely satisfy 


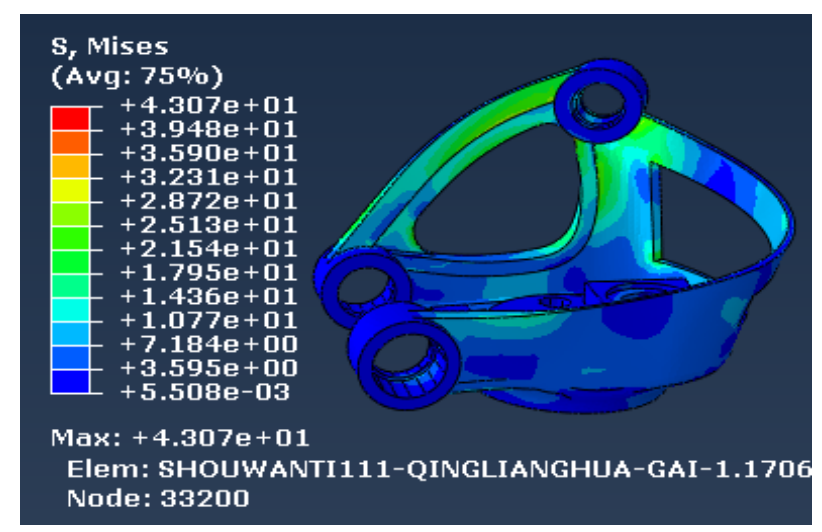

Fig. (18). The stress cloud of wrist.

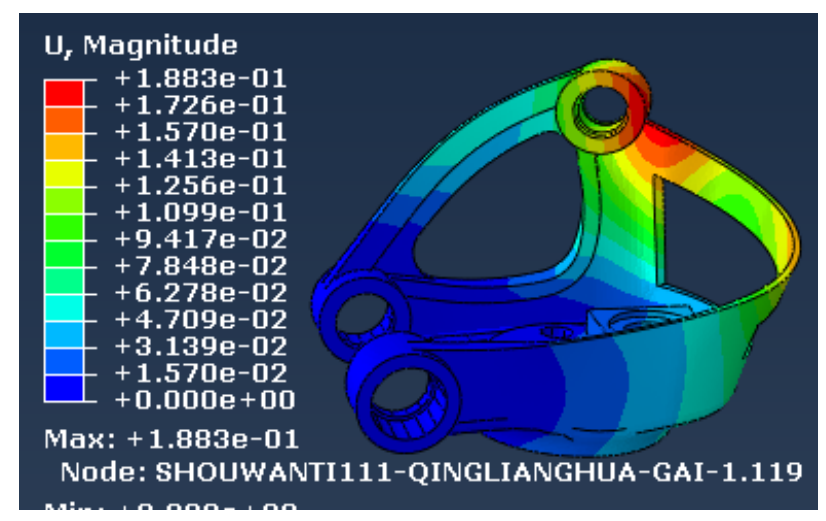

Fig. (19). The displacement cloud of wrist.

Table 1. Comparison results before and after optimization.

\begin{tabular}{|c|c|c|c|c|c|c|}
\hline \multirow{2}{*}{ Part Name } & \multicolumn{3}{|c|}{ Before } & \multicolumn{2}{c|}{ After } \\
\cline { 2 - 7 } & Mass (kg) & $\begin{array}{c}\text { Maximum Stress } \\
\text { (MPa) }\end{array}$ & $\begin{array}{c}\text { Maximum Displacement } \\
(\mathbf{m m})\end{array}$ & Mass (kg) & $\begin{array}{c}\text { Maximum } \\
\text { Stress (MPa) }\end{array}$ & $\begin{array}{c}\text { Maximum Displacement } \\
\text { (mm) }\end{array}$ \\
\hline \hline Wrist & 44.91 & 36.64 & 0.1297 & 39.40 & 43.07 & 0.1883 \\
\hline Forearm & 148 & 37.78 & 1.097 & 135 & 87.85 & $12.27 \%$ \\
\hline
\end{tabular}

their location accuracy requirement. The mass of forearm is reduced from 148 to 135 and the reduced percentage is $8.78 \%$. The mass of wrist is reduced from 44.91 to 39.40 and the reduced percentage is $12.27 \%$.

\section{CONCLUSION}

The structural optimization design of ER300 palletizing robot by using finite element analysis technology is discussed in this paper in detail. We also validate the finite element analysis results by Stress and strain experiment. This research seeks to get more reasonable, lightweight and energy-saving structure on the basis of insuring the performances of ER300 palletizing robot, and to provide the design reference for ER300 palletizing robot. The main results of this research can be concluded as follows:
1. The stress cloud and displacement cloud of the parts before structure optimizations by analysis of ABAQUS are obtained, which provides the basis for the optimization design.

2. To ensure the reliability of the results of the analysis, stress and strain experiment is carried out to validate the analysis results.

3. The contrastive curves of experimental results and finite element's result are obtained and have ensured the reliability of the finite element analysis results.

4. Structural optimization is researched, which meets the design requirements for the ER300 palletizing robot and the stress cloud and displacement cloud of the parts after structural optimization are obtained. 
5. The total mass of the forearm after structure optimization changes into $135 \mathrm{~kg}$ and it is reduced by $13 \mathrm{~kg}$ compared with the initial model. The total mass of the wrist after structure optimization changes into $39.40 \mathrm{~kg}$ and it is reduced by $5.51 \mathrm{~kg}$ compared with the initial model.

Finite element structural optimization technique not only can assure stiffness, strength and other performances requirements of ER300 palletizing robot, but also can greatly reduce the use of materials and make the machine run more flexible by structural optimization design. However in this paper we focus on analyzing the structural optimization, manufacturing process of the parts isn't considered after structural optimization. Research on energy-saving optimization design of palletizing robot should be the future direction.

\section{CONFLICT OF INTEREST}

The authors confirm that this article content has no conflict of interest.

\section{ACKNOWLEDGEMENTS}

This work was financially supported by Prospective joint research project of Jiangsu Province(APP NO. BY201500405), ESTUN ROBOTICS and "excellence plans-zijin star" Foundation of Nanjing University of Science. The supports are gratefully acknowledged.

\section{REFERENCES}

[1] L. Gang, and J. Liu, "Research and application situation, problems and solutions of palletizing robots", Packaging Engineering, vol. 32, no, 3, pp. 102, 2011.

[2] R. Bloss, "Robots use machine vision and other smart sensors to aid innovative picking, packing and palletizing", Industrial Robot, vol. 40 , no. 6 , pp. 525-529, 2013.

[3] L. Qian, L. Guangliang, and S. Jie, "The structure analysis and performance research on palletizing robot body", Equipment Manufacturing Technology, vol. 11, pp. 4-6, 2011.

[4] W. Puquan, H. Qingzhong, Z. Ming, W. Zhipeng, and G. Shuai, "Static analysis and optimization of polyarticular palletizing robots", Packaging Engineering, vol. 23, pp. 77-79, 2013.
[5] S. Shital, N. Chiddarwar, and B. Ramesh, "Conflict free coordinated path planning for multiple robots using a dynamic path modification sequence", Robotics and Autonomous Systems, vol. 59, pp. 508-518, 2011.

[6] Z. K. Huang, "A new image thresholding method based on gaussian mixture model," Applied Mathematics and Computation, vol. 205, no. 2, pp. 899-907, 2008.

[7] R. Taormina, "Neural network river forecasting with multiobjective fully informed particle swarm optimization," Journal of Hydroinformatics, vol. 17, no. 1, pp. 99-113, 2015.

[8] C. L. Wu, "River stage prediction based on a distributed support vector regression," Journal of Hydrology, vol.358, no. 2, pp. 96$111,2008$.

[9] C. T. Cheng, "Long-term prediction of discharges in Manwan Reservoir using artificial neural network models," Lecture Notes in Computer Science, vol. 3498, pp. 1040-1045, 2005.

[10] K.W. Chau, "Application of a PSO-based neural network in analysis of outcomes of construction claims," Automation in Construction, vol. 16, no. 5, pp. 642-646, 2007.

[11] R. Kala, "Multi-robot path planning using co-evolutionary genetic programming", Expert Systems with Applications, vol. 39, pp. 3817-3831, 2012.

[12] G. Xuan, and R. Cheng, Genetic algorithms and engineering optimization, Tsinghua university press: Beijing, 2004.

[13] N. Luan, H. Zhang, and S. Tong, "Optimum motion control of palletizing robots based on iterative learning", Industrial Robot, vol. 39, no. 2, pp. 162-168, 2012.

[14] L. Sun, Y. Luo, X. Ding and L. Wu, "Path planning and obstacle avoidance for mobile robots in a dynamic environment", The Open Automation and Control Systems Journal, vol. 13, pp. 77-83, 2014.

[15] Z. Xiaguang and F. Dongxiao, "Influence of Biped Robot's Walking Parameters on its Stability", The Open Automation and Control Systems Journal, vol. 13, pp. 341-348, 2014.

[16] L. Chuanlong, G. Gang, and Z. Haining, "kinematics analysis and simulation of the 4-dof hybrid stacking robot", Manufacture Information Engineering of China, vol. 6, pp. 23-28, 2011.

[17] M. Jiancai, Z. Lei, and Z. Weiling, "ABAQUS-based modal analysis for parallel robot palletizer", Hoisting and Conveying Machinery, vol. 11, pp. 51-54, 2013.

[18] J. Li, B. Duan, and Q.Nan, "Kineto-static analysis on a TH50 type palletizing robot", Journal of University of Science and Technology Beijing, vol. 4, no. 33, 2011.

[19] L. Yang, G. Zhihui, Y. Chao, and L. Yiwu, "Kinematics Analysis and Simulation of the Hybrid Stacking Robot", Machinery \& Electronics, vol. 3, pp. 57-60, 2010.

[20] Z. Lei, D. Qiang, and Z. Dandan, "Finite element analysis of palletizing robot arm based on ABAQUS", Mechanical Engineer, vol. 9, pp. 119-121, 2013.

Received: January 13, 2015

Revised: April 02, 2015

Accepted: April 10, 2015

(C) Kunpeng et al.; Licensee Bentham Open.

This is an open access article licensed under the terms of the Creative Commons Attribution Non-Commercial License (http://creativecommons.org/licenses/by-nc/3.0/) which permits unrestricted, non-commercial use, distribution and reproduction in any medium, provided the work is properly cited. 